\title{
Wild oat competition in short-statured wheat
}

\author{
David W. Cudney $\square \quad$ Lowell S. Jordan $\square \quad$ Warren E. Bendixen
} Jodie Holt $\square$ A. E. Hall $\square$ Chris J. Corbett $\square$ John S. Reints

\begin{abstract}
Wild oat and wheat were synchronized in their development and were shown to be equally competitive in southern California studies. Competition effects of wild oat were most evident in wheat after the stem elongation stage.
\end{abstract}

A serious pest of small grains in California, wild oat (Avena fatua) germinates with wheat, oats, and barley and competes with these crops throughout their growth cycle. Wild oat can reduce grain and forage yields and quality.

Wheat has been a particular victim to wild oat competition in recent years, as new, shorter-statured wheat cultivars have come

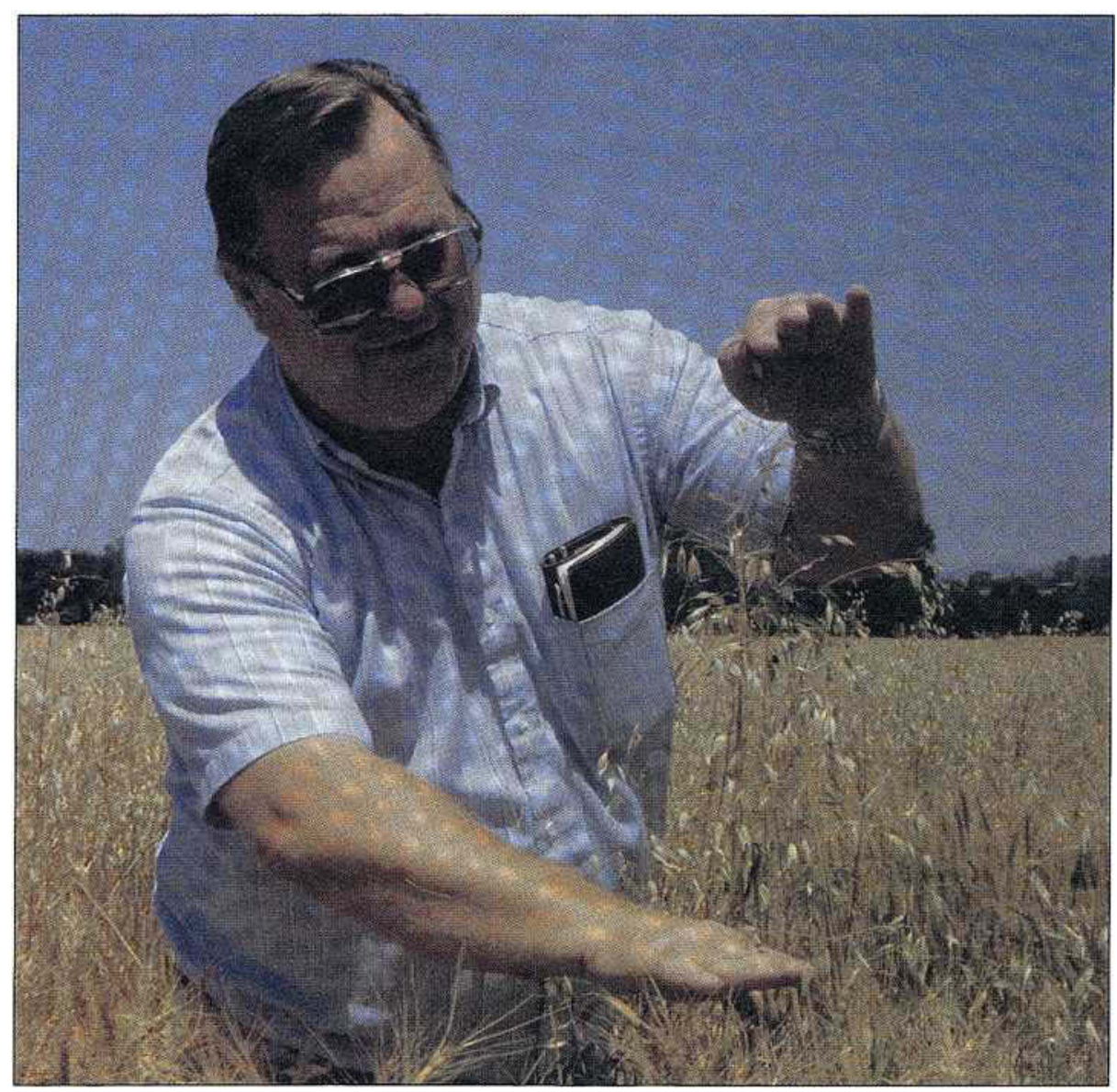

Santa Barbara County Farm Advisor Warren Bendixen shows the height differentiation at maturity between wild oats and wheat. growers and consultants assess wild oat population thresholds for herbicide treatments. An overall assessment of the critical interactions of wheat and wild oat would help us understand the competitive relationships between the two species. For all of these reasons, we undertook a 3-year study in irrigated wheat at UC Riverside and an additional field study in the Santa Ynez region of south-central coastal California.

\section{Materials and methods}

Five field experiments were conducted at the UC Riverside Agricultural Experiment Station. The five planting dates were January and February in 1985 and 1986, and February in 1987. The soil was a sandy loam. We established wild oat populations by uniformly sowing pre-weighed quantities of seeds into plot areas. The plot areas were then harrowed 2 inches deep to incorporate the seeds. The seeds had been harvested in previous seasons from commercial fields in the region. Plots were then planted with preweighed amounts of wheat seeds using a small-graindrill. Rows of wheat were spaced a standard 6 inches apart with eight rows per plot. Plots averaged 75 feet long. The wheat cultivar 'Anza,' a short-statured, hard red spring wheat commonly grown in southern California was used.

To reduce interactions of moisture and nutrient competition, we grew all plots with amplesoil moisture and nitrogen. Plots were sprinkler-irrigated weekly until the stem elongation stage, at which time we shifted to twice-weekly irrigation until crop maturity. Each sprinkler application averaged 1 inch of water. Soil nutrient analysis showed adequate phosphorus and potassium. Additional nitrogen was applied as urea through a preplant application of $100 \mathrm{lb}$ nitrogen per acre and a side-dress application at the tillering stage of $75 \mathrm{lb}$ per acre.

Experiments at Riverside were a composite of additive and replacement series designs. The additive series consisted of wheat planted at a density of 20 plants per square foot, averaged over the five experiments. Four densities of wild oat were then added to the wheat: $0,8,13$ and 21 plants per square foot, average.

The replacement series consisted of monoculture plots of wheat and wild oat averaging 20 and 25 plants per square foot, respectively. Mixtures of wheat and wild oat were established in plots to obtain proportional ratios of $33 \%: 67 \%$ and $67 \%: 33 \%$ of wheat and wild oat, respectively. Each experiment was replicated four times in randomized complete blocks.

Six wheat and six wild oat plants from each plot in mixed and pure populations were chosen at random and flagged so we could monitor them for stage of development throughout the growing season according to the Haun scale. The Haun scale is a means 


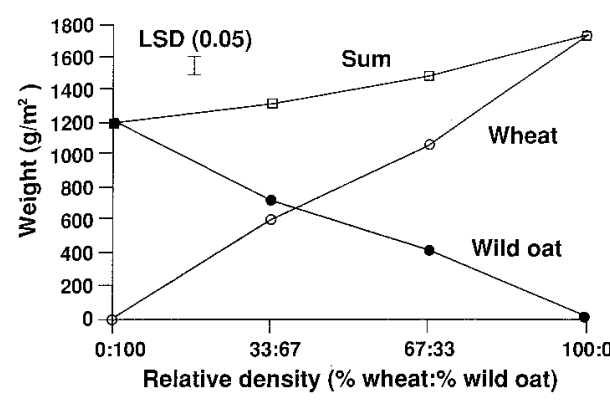

Fig. 1. Wheat and wild oat grew with nearly equal competitiveness in our field trials, as shown above.

of monitoring the main stem development of grass species. Leaves along the main stem of wheat and wild oat were numbered and recorded as each whole leaf or fraction of a leaf appeared from emergence to the last full leaf (Haun stages 1 to 9). After the last leaf emerged, elongation of the eighth internode (Haun stage 10), swelling of the ninth leaf sheath or boot (Haun stage 11), emergence of the head (Haun stage 12), and elongation of the peduncle (Haun stage 13) were recorded. Wealso recorded the canopy height of both wheat and wild oat.

Harvests were made at tillering, stem elongation, flowering, and maturity. Leaf area and biomass of each species were measured along with grain yield at maturity. In subplots, weremoved wild oat from wheat at each of the four stages. An additional subplot was included in the 1986 and 1987 experiments in which we trimmed wild oats to the level of the wheat canopy every day after the stem elongation stage.

\section{Results and discussion}

Analysis of variance of the Haun developmental stage data taken for each experiment at UC Riverside and Santa Ynez revealed no significant difference in the development of the main stem of wheat in any of the experiments when the density of the compet-

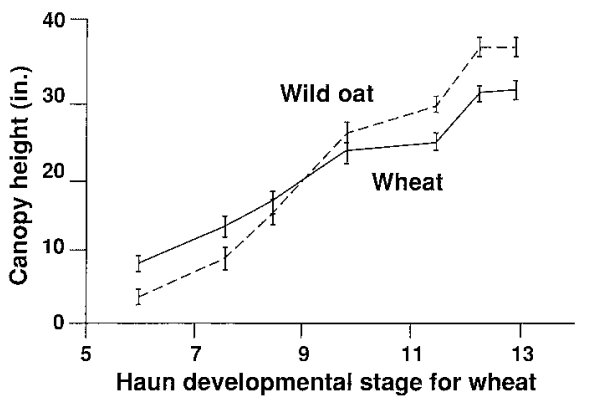

Fig. 2. Canopy height of wheat and wild oat, January 1985 planting. Beginning with stem elongation, wild oat begins to grow taller than wheat, and to shade the crop. Vertical bars indicate $L S D$ at $P=0.05$.

ing wild oat was varied. Similarly, the developmental stages of the main stem of wild oat did not differ between pure culture and mixed cultures with wheat. Also, the developmental rates of wheat and wild oat did not significantly differ.

In an effort to provide more uniformity in our measurements of the developmental rates overdifferentenvironmentalconditions (e.g., location, planting date, year), we substituted a measure of physiological time, degree days, for chronological time. We arrived at our base temperature for degreeday calculation by taking the rate of development (Haun stages per day) from emergence to Haun stage 13 for the six experiments and plotting itagainst the average temperature for that period. A base temperature of $40^{\circ} \mathrm{F}$ was estimated by leastsquares regression. Regression analysis of plant development for all six experiments taken together gave a better fit when we used degree days as the unit of time.

The shoot dry weight (biomass) of each species at harvest declined in direct proportion to the increase of the other species' shoot dry weight (fig. 1), so the combined biomass of both species at each treatment was similar to that of either species grown alone. Apparently, both species were competing for shared resources, and each made

Table 1. Effect of time of wild oat removal and clipping on wheat seed yields (yields are averages of all three wild oat densities)

\begin{tabular}{|c|c|c|c|c|c|c|}
\hline \multirow{3}{*}{$\begin{array}{l}\text { Wheat growth } \\
\text { stage at wild } \\
\text { oat removal }\end{array}$} & \multicolumn{5}{|c|}{ Yield for planting date } & \multirow{3}{*}{$\begin{array}{l}\text { Ave. reduction } \\
\text { in wheat yield } \\
\text { from wild oat } \\
\text { interference }\end{array}$} \\
\hline & \multicolumn{2}{|c|}{1985} & \multicolumn{2}{|c|}{1986} & \multirow{2}{*}{$\frac{1987}{\text { Feb. }}$} & \\
\hline & Jan. & Feb. & Jan. & Feb. & & \\
\hline & \multicolumn{5}{|c|}{. } & $\%$ \\
\hline $\begin{array}{l}\text { No wild oat } \\
\text { in field }\end{array}$ & 8,990 & 9,022 & 5,501 & 5,456 & 4,770 & 0 \\
\hline \multicolumn{7}{|l|}{ Removal at: } \\
\hline $\begin{array}{l}\text { Wheat tillering } \\
\text { Stem }\end{array}$ & 8,674 & 8,122 & 6,196 & 5,108 & 4,413 & 2 \\
\hline elongation & 8,327 & 7,096 & 5,287 & 5,438 & 4,137 & 9 \\
\hline Anthesis & 7,132 & 4,770 & 3,325 & 3,753 & 3,147 & 33 \\
\hline $\begin{array}{l}\text { No removal } \\
\text { Wild oat }\end{array}$ & 5,830 & 4,502 & 2,969 & 3,504 & 3,138 & 41 \\
\hline clipped only & - & - & 3,878 & 3,899 & 3,611 & 28 \\
\hline $\operatorname{LSD}(0.05)$ & 499 & 704 & 571 & 481 & 428 & \\
\hline
\end{tabular}

similar demands for these environmental factorssuch that the two species were equally competitive. Wild oat and wheat were similar in competitive ability even though wild oat had less leaf area per plant. A late season height and shading advantage for wild oat might make up for the leaf area disadvantage.

There were no significant differences in height for either wheat or wild oat as population densities varied for any of the experiments. In every test, wild oat was shorter than wheat (fig. 2) until Haun stage 8 or 9 (mid- to late-stem elongation stage). Wild oat then grew more quickly, and its final canopy was 5 to 10 inches taller than that of wheat.

The results of the removal studies from Riverside in 1985, 1986, and 1987 are presented in table 1 . The removal of wild oat at tillering of wheat resulted in no reduction in wheat yield. Removing wild oat either at stemelongation or atflowering or no removal of wild oat resulted in progressively greater reductions in wheat yield. The most dramatic reduction in wheat yield occurred when wild oat was removed after stem elongation, indicating thatcompetition was greatestafter this time.

When we clipped wild oat leaves to prevent them from emerging above the wheat canopy, wheat yield increased significantly. The clipping experiment showed the importance of the shade cast by wild oat's higher canopy late in the season.

\section{Summary}

The development of wheat and wild oat was synchronized from emergence through flowering. This illustrates the ability of wild oat to perform as a crop mimic. When different planting dates and years were compared, degree days gave a better fit of developmental rates than did calendar days. Utilizing the regression equation and degree days, the Haun development of both wheat and wild oat could be predicted. Density and yield comparisons revealed that wheat and wild oat were equally competitive on per plant basis. This was true even though wild oat had less leaf area per plant than did wheat. Wild oat has a height advantage over wheat in late season which results in shading and yield reduction.

David W. Cudney is Extension Weed Scientist, Lowell S. Jordan is Professor of Horticulture and Plant Physiology, A. E. Hall is Professor of Plant Physiology, Jodie Holt is Associate Professor of Plant Physiology, Chris J. Corbett is Staff Research Associate, Plant Pathology, and John S. Reints is Staff Research Associate, Botany and Plant Science, all at UC Riverside; and Warren E. Bendixen is Cooperative Extension Farm Advisor, Santa Barbara County.

The research effort reported here was supported by a grant from the Statewide Integrated Pest Management Project. 